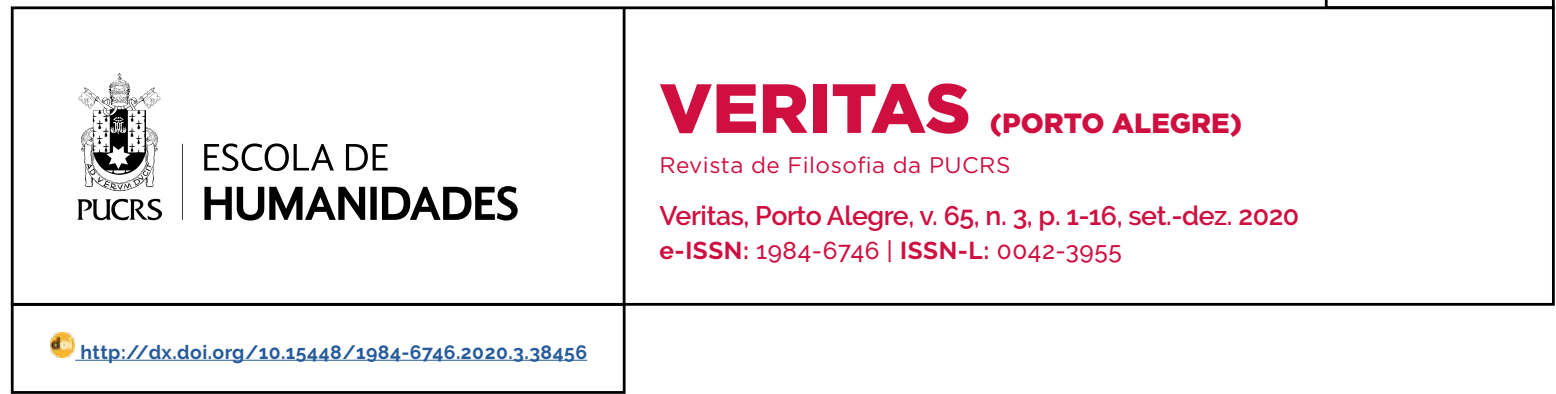

SEÇÃO: EPISTEMOLOGIA \& FILOSOFIA DA LINGUAGEM

\title{
A face estética da epistemologia pragmaticista de Peirce ${ }^{\mathbf{1}}$
}

\author{
The esthetic face of Peirce's pragmaticistic epistemology \\ El rostro estético de la epistemología pragmática de Peirce
}

\section{Ivo A. Ibri²}

orcid.org/0000-0003-3801-3061 ibri@uol.com.br

Recebido em: $12 / 6 / 2020$. Aprovado em: $10 / 8 / 2020$ Publicado em: 12/01/2021.

\section{(c) (1)}

Artigo está licenciado sob forma de uma licença Creative Commons Atribuição 4.0 Internacional.
Resumo: A Estética, uma das ciências normativas da filosofia de Peirce, não tem por objeto o Belo, mas o Admirável, como sabem os estudiosos de sua obra. Contudo, não é imediatamente evidente essa distinção, uma vez que Admirabilidade traz em seu interior o predicado da beleza também. Quais, então, seriam as relações entre ambos esses conceitos? Por que a admirabilidade se credenciaria a ser um fim em si mesma da Estética e se constituir no fim último da Ética? Qual a natureza da experiência estética e como ela pode subsidiar a identificação do que seja o Admirável? Partindo da insistência de que há uma rede de conceitos na filosofia de Peirce, da Fenomenologia à sua Metafísica, que fornece um rico vocabulário para se refletir sobre tais questões, esse ensaio busca mostrar que há na natureza epistemológica do pragmaticismo uma eticidade que embora seja necessária não the é suficiente, requerendo-se que a Estética forneça os fins das ações que constituem revelação dos conceitos, à luz das categorias peircianas consideradas estruturantes das relações entre mundos interno e externo, tomados sob uma ótica radicalmente realista.

Palavras-chave: Peirce. Epistemologia. Pragmaticismo. Estética. Etica.

\begin{abstract}
Esthetics, as one of Peirce's normative philosophies, does not have Beauty as its object, but the Admirable, as scholars of his work know. However, this distinction is not immediately apparent, since Admirability also carries within it the predicate of Beauty. What, then, would be the relationship between both these concepts? Why should the admirable qualify as an end in itself of Esthetics, and constitute the ultimate end of Ethics? What is the nature of esthetic experience, and how can it aid the identification of the Admirable? Based on the insistence that there is a net of concepts in Peirce's philosophy, from Phenomenology to his Metaphysics, which provide a rich vocabulary to reflect on these issues, this essay seeks to show that there is in the very epistemological nature of pragmaticism an ethicity that, while necessary, is insufficient, demanding that Esthetics provide the ends of the actions that constitute the revelation of concepts, in light of the Peircean categories regarded as structural for the relations between internal and external worlds, under a radically realist viewpoint.
\end{abstract}

Keywords: Peirce. Epistemology. Pragmaticism. Esthetics. Ethics.

Resumen: La Estética, una de las ciencias normativas de la filosofia de Peirce, no tiene lo Bello como objeto, pero lo Admirable, como saben los estudiosos de su obra. Todavía, no es inmediatamente evidente esta distinción, una vez que la Admirabilidad también trae en su interior el predicado de la belleza. ¿Cuáles, entonces, serían las relaciones entre ambos conceptos? ¿Por qué la admirabilidad se habilitaria a ser un fin en si misma de la Estética y a constituirse en el fin último de la Ética? ¿Cuál es la naturaleza de la experiencia estética y como ella puede subsidiar la identificación de lo que sea lo Admirable? Iniciando por la insistencia de que hay una red de conceptos en la filosofía de Peirce, de la Fenomenología a su Metafísica, que proporciona un rico vocabulario para reflexionar sobre esas cuestiones, este ensayo busca mostrar que en la naturaleza

\footnotetext{
Este artigo é uma versão significativamente ampliada e revisada de versão parcial publicada em inglês como IBRI, Ivo. Linking the Aesthetic and the Normative in Peirce's Pragmaticism: A Heuristic Sketch: Charles S. Peirce Society 2016 Presidential Address. Trans-actions of the Charles S. Peirce Society, v. 52, n. 4. p. 598-610, Fall 2016. A reprodução em português da parcela constante desse original em inglês foi devidamente autorizada pelos editores da revista.
}

Pontifícia Universidade Católica de São Paulo (PUCSP), São Paulo, SP, Brasil. 
epistemológica del pragmaticismo hay una eticidad que aunque sea necesaria no le es suficiente, requiriéndose que la Estética ofrezca los fines de las acciones que constituyen revelación de los conceptos, a la luz de las categorias peirceanas consideradas estructurantes de las relaciones entre los mundos interno y externo, tomados bajo una óptica radicalmente realista.

Palabras clave: Peirce. Epistemologia. Pragmaticismo. Estética. Ética.

"Numa palavra, não se pode mais perguntar como ele (o homem) passa da beleza à verdade, pois esta já está em potência na primeira"

(Schiller [Letter XXV])

\section{Introdução: uma filosofia para ser continuada}

Peirce nunca pode finalizar um livro e publicá-lo; e especialmente nenhum livro sobre a uma possivel face estética do pragmaticismo. Isso não é apenas uma nota de caráter histórico, mas tem um significado mais profundo, suponho. Quando um autor está envolvido com o processo de publicar um livro, é seu privilégio e direito rever seus escritos, numa oportunidade de modificar termos, suprimir palavras ou modificá-las, acrescer sentenças esclarecedoras, notas de rodapé etc. Deve-se reconhecer que Peirce não teve essa oportunidade - caso tivesse ela ocorrido, possivelmente ele teria apurado algumas partes de seus escritos, evitando-se interpretações que se apegam muito mais à letra que ao espírito da obra. Esse exercício de apreensão do espirito é bem-sucedido, penso eu, quando, de um lado, nos familiarizarmos com o texto do autor e, de outro, talvez o mais importante e que dá início a essa apreensão, quando o texto desperta um sentimento de simpatia em quem o estuda. Essa tem sido minha abordagem ao pensamento de Peirce, desde longa data, seja por razão intelectual ou pessoal.

Composta por uma quantidade enorme de manuscritos e uma pequena parte de ensaios publicados, a obra de Peirce ainda assim apresenta uma unidade que se consolida gradativamente com os textos de maturidade. Ouso dizer que supor ter encontrado radicais mudanças de opinião, tais que haveria um primeiro Peirce e outras possiveis faces teóricas que se the seguiram, é se prender demasiadamente na letra, talvez imbuindo-se de estratégias dedutivas na busca de contradições, fragmentando uma obra que, a meu ver, se pautou pelo esforço de construir um sistema de teorias que pudesse dialogar com todos os problemas da Filosofia. Se alguns diálogos não foram estabelecidos por Peirce, malgrado, ironicamente, sua imensa obra, é que lhe faltou tempo de vida para fazê-lo. Por isso, aqueles que se dispuserem a encontrar um sistema de teorias que se imbricam de modo logicamente harmônico, devem ter em conta uma atitude de estudioso da obra peirciana dotada de uma boa vontade critica. Essa, em algumas passagens, se efetivará por perceber o que deveria ter sido dito e não, ao modo estruturalista de análise filosófica, apenas se prende à letra.

O nascimento de tal boa vontade critica parece-me seguir-se à apreensão do espirito da obra, conceito que, aliás, é clássico em filosofia. Sem evidentemente se abdicar de um espirito crítico de análise, essa boa vontade decorre em parte da consciência de que se lê um autor que não pôde revisar a maior parte de sua obra. É evidente, também, que essas considerações advêm de minha experiência pessoal de contato com a obra de Peirce, e uma longa convivência com as ideias de alguém, com o símbolo semiótico que significa pragmaticamente o que se poderia chamar de alma, pode suscitar relações agápicas que acabam por alimentar aquilo que chamei de boa vontade. Entenda-se a adoção dessa expressão como algo destituido de atitude moral de principio, mas que é despertada por algumas promessas de rica recompensa, a saber, de remunerar essa atitude com uma miríade de novas ideias que ensejam descobertas originais em filosofia.

A esse respeito, em um ensaio sobre ontologia da arte $^{3}$, utilizei uma metáfora que me parece bastante justa para, de modo geral, caracterizar a obra de Peirce: um sistema teórico que, consi- 
derando meu próprio background científico e da engenharia, a exemplo da teoria das afinidades químicas, apresenta "valências abertas", ou seja, uma disposição para combinar ideias em redes teóricas mais amplas, gerando uma competência de abordagem nova de antigos e novos problemas. Também propus o termo "sementes", para caracterizar justamente o que o sistema teórico de Peirce lega para sua continuidade na forma de sugestões heuristicas para desenvolver novas visões de diversas áreas da cultura, não apenas no que respeita à introdução de um novo vocabulário, como o da Semiótica, por exemplo, mas introduzindo abordagens mais profundas dos problemas especíicos de cada uma delas. Cito, exemplarmente, áreas que ainda estão abertas a essa abordagem, como a arte e a psicanálise, nas quais, não obstante poucos, interessantes trabalhos já se encontram desenvolvidos. ${ }^{4}$

Para uma primeira percepção de um sistema filosófico em Peirce, é necessário, ao menos, considerar a triade das ciências que compõem a Filosofia, tendo em conta sua hierarquia de dependências que, ao fim e ao cabo, expressam a relação de dependência entre as categorias peircianas. Suponho que uma leitura mais fiel do autor se faz por considerar seriamente que a Filosofia se inicia por uma Fenomenologia, ponto de partida que deveria evitar interpretações transcendentalizadas das ciências normativas que se seguem a essa ciência. Nada credencia buscar, na Lógica ou Semiótica, Ética e Estética, fundamentos transcendentes que as possam constituir. O início por um "estar no mundo", como tenho afirmado em outros ensaios, dado pelo oceano de experiência que cerca nossa humana condição geneticamente fenomenológica, condiciona, pelo que ela venha implicar para as ciências que se seguem, uma linha de filosofia. Não se trata, como se sabe, de uma redução fenomenológica, a exemplo do projeto de Husserl para sua Fenomenologia. O que constitui a realidade não pode ser reduzido ao que aparece, deixando à subjetividade a articulação significativa dos dados empíricos, repetindo um projeto de natureza kantiana que, tácita ou explicitamente, assimetriza, de gênese, pelo seu nominalismo, homem e Natureza. ${ }^{5}$ Tal assimetria é de Forma, conceito de que vou me valer e definir na continuidade desse ensaio.

A Fenomenologia de Peirce funda suas três categorias, e elas vão moldar toda sua filosofia, como sabem sobejamente os estudiosos do autor. ${ }^{6}$ A propósito, tenho denominado essa presença universal das categorias em todos os conceitos desenvolvidos por Peirce de simetria categorial, pela sua validade indistinta tanto para as mentes cognitivamente representantes quanto para os objetos representados, buscando-se evitar, por questões de inadequação de vocabulário, atribuir-se tal simetria à relação sujeito-objeto, muito utilizada em filosofias nominalistas, em que sobressai a figura de um sujeito constituidor. Porém, não me parece ter sido até agora profundamente explorada pela análise da obra do autor as implicações que tal universal validade das categorias representa. Sua consequência mais significativa é que nenhuma apropriação nominalista de sua filosofia poderia ser legitimada - afirmo que simetria se sugere como um bom termo para caracterizar o realismo que é marca diferenciadora da filosofia peirciana. ${ }^{7}$

Não se trata apenas de um realismo contemporâneo que polemiza sobre a existência ou não de um mundo externo à mente humana, mas, fiel à sua origem escolástica ${ }^{8}$ depois generalizada por Peirce pela lógica dos relativos, propõe que os fenômenos se encontram sob relações gerais reais que lhes são associadas, independentemente de as representarmos como tais. A propósito, a ideia de tal independência tem gênese na experiência fenomenológica de segundidade, na qual é praticamente onipresente a reação do mundo às nossas arbitrárias concepções sobre ele ou a

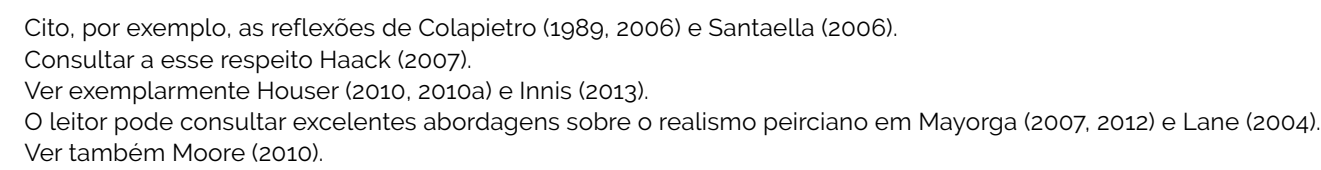


atos de vontade que promovem nossas ações. Essa é a experiência que requer a consideração de uma faticidade que transcorre independente de nós e que, aliás, dá o eixo da definição de realidade adotada por Peirce. ${ }^{9}$

A crença em um mundo que é indiferente a nossas concepções sobre ele sustenta-se nas previsões eventualmente equivocadas que fazemos, caracterizando o que Peirce denomina reação dos fatos duros. Esse é um quesito simples, se se tem a Fenomenologia tomada a sério como ponto de partida para o fazer filosófico. De fato, é fácil reconhecer que estamos continuamente pensando o curso futuro dos eventos: "Cinco minutos de nossa vida desperta dificilmente passarão sem que façamos algum tipo de previsão"10. Muitas vezes os fatos caminham em uma direção e nossas previsões indicavam outra totalmente distinta. Quando ambas as trajetórias coincidem e têm um grau razoável de redundância, desenvolvemos hábitos de ação e consequentes crenças nos procedimentos que o hábito enseja pôr em prática. Já aqui, a Fenomenologia, ao realçar a importância dessa classe de experiência, que é um dos fulcros da segunda categoria, anuncia as bases para se refletir sobre aquele quesito de alteridade que caracterizará o cerne do conceito de realidade. Não apenas nas previsões erradas experienciamos essa reação dos fenômenos. Eles, por vezes, invadem nossa vida cotidiana sem ser convidados, demonstrando, para além da alteridade reativa às nossas ações, sua proverbial insolência. Em ambos os casos, contudo, temos também a experiência de buscar mediações que são o resultado das interpretações que fazemos dessa experiência de segundidade.

Tais mediações são a mais imediata aplicação de nossa racionalidade para minimizar o choque bruto dos fatos. Mediações dinâmicas, ou interpretantes dinâmicos, tomam em conta um diálogo vivo com a experiência, do qual não podem se furtar, sob pena de perda da eficiência mediadora.
As melhores mediações são aquelas que de fato se constroem pelo esforço de representar a conduta espaçotemporal do objeto da experiência. Até então, toda essa simples descrição não é mais que ligada à vida prática, de fato o terreno mais genuino em que se inicia a filosofia de Peirce. As crenças são necessárias para a vida corrente e, por essa razão, não são ficticiamente fragilizadas por dúvidas oriundas de especulações teóricas. Comprovar fenomenologicamente que crenças não são quebradas por meras teorias, uma vez que o lado externo de tais crenças, a conduta, não se modifica e, assim, evidencia a permanência e a operacionalidade da crença nas formas determinadas de ação, já anuncia o princípio de caráter semântico do Pragmatismo. ${ }^{11}$

A aparentemente despretensiosa Fenomenologia propõe-se a um inventário das classes de experiência generalizando-as quanto a seu modo de ser, não a seu conteúdo - isso evidentemente seria impensável face à diversidade imensurável da história fática das experiências individuais. É, assim, notável que tais modos de ser sejam sintetizados em apenas três classes ou categorias; a par da segundidade, a experiência de construir mediações em face da alteridade envolve formas cognitivas a respeito da conduta do objeto, procedimentos indutivos que geram hábitos e que, como dito anteriormente, atuam como mediações, caracterizando a categoria da terceiridade.

A atividade de pensar, julgar logicamente, parece ser uma experiência muito fácil de ser reconhecida - talvez seja a mais familiar para os filósofos. De sua vez, embora a segundidade, em sua simplicidade fenomenológica, seja aparentemente trivial, afirmo que há sistemas de filosofia que, uma vez submetidos a uma análise mais profunda, evidenciariam não considerar a alteridade dos objetos de cognição, como, exemplarmente, são os sistemas que propõem a constituição da realidade do objeto pelas teorias a seu respeito. Mais dificil ainda seria, nesses casos, o reconheci-

\footnotetext{
9 CP 1.325; CP 7.659. PEIRCE, Charles Sanders Peirce. Collected Papers of Charles Sanders Peirce. Edited by Charles Hartshorne, Paul Weiss, and Arthur W. Burks. Cambridge, Massachusetts, Harvard University Press, 1931-1935, 1958. 8 v. Fazemos referência a esta obra na forma usual: CP indica Collected Papers; o primeiro número designa o volume e o segundo o parágrafo.

10 CP 1.26

11 Ver a esse respeito a abordagem de Liszka (2009).
} 
mento de formas lógicas próprias ao objeto e que, em verdade, o constituiriam independentemente de qualquer cognição. Caso essa consideração e esse reconhecimento ocorressem, tais filosofias seriam caracterizadas como realistas, ao modo da filosofia peirciana. Pode-se dizer, não obstante, serem elas raramente encontráveis na história da filosofia, principalmente na contemporaneidade. ${ }^{12}$

Creio que a maioria dos estudiosos de Peirce, a exemplo de Dewey, concordaria que a primeiridade é a categoria mais original do autor, pela sua formulação geneticamente fenomenológica descrita como vivências desinteressadas, que desmobilizam de princípio a vontade e, com ela, a necessidade do agir intencionado para algum fim. Olhar o mundo sem querer algo é isentar-se das reações que ele oferece sempre que agimos, possibilitando, por consequência, prescindir de mediações. Essa relação com o mundo permite vê-lo sem a generalidade do conceito que seleciona dele apenas o que pode conceitualmente ser interpretado. Há, então, essa repousante possibilidade de prescindir das classes de experiência associadas à segundidade e à terceiridade. Esse estado da mente que, de alguma forma, se exime de julgar o que vê e apenas sensivelmente experimenta porque desmobiliza o sentimento de querer e, assim, a necessidade de um agir intencionado, possibilita subtrair-se da temporalidade que está implicada nos conceitos, um ponto importante ao qual retornarei. Eles, os conceitos, mobilizam a memória de um saber generalizado e propõem uma visão preditiva dos fatos futuros decorrentes do estado de coisas que se põe diante da mente. O tempo está sempre implicado em nossas experiências de terceiridade, enquanto a segundidade bruta é aqui e agora; experienciá-las, como tais, se dá em um ponto do tempo, em um determinado instante, e sua eventual redundância e regularidade temporais ensejam pensar que ela esteja sob alguma lei, implicando, assim, em terceiridade. ${ }^{13}$
A mediação dos conceitos nos faz perceber os objetos apenas enquanto eles se inserem em classes de predicados. Mas uma classe de predicados destaca dos particulares que lhe pertencem aquilo que eles têm em comum com os demais de sua espécie. Tais classes recebem nomes, e é assim que a linguagem dos conceitos se alimenta das semelhanças que constituem os predicados generalizados. A linguagem assim constituída por conceitos que, de sua vez, atuam como mediações diante da realidade, dão forma à nossa percepção dos objetos, vendo-os segundo o que partilham por semelhança com os demais congêneres. Entretanto, Peirce chama nossa atenção para um aspecto dos fenômenos que ficam à margem desse processo mediativo que nossa racionalidade cognitiva constrói como forma de balizar nossas ações futuras, minimizando a possibilidade de errarmos com respeito aos fins que queremos. Queremos fazer escolhas, não meramente apostas:14 para tanto, nossa leitura do mundo precisa apreender dele o que tem continuidade de forma, facultando-nos fazer previsões sobre o curso futuro dos fatos. Nossa racionalidade se expressa, assim, geneticamente prática, por estarmos imersos no oceano de fenômenos no qual a reflexão filosófica tem sua mais direta origem. ${ }^{15}$

Esse início da filosofia proposto por Peirce molda geneticamente a sua face e faz com que o pragmatismo emane dele quase naturalmente. As consequências práticas de sua máxima não são mais que a relação entre os modos como interpretamos nossa humana experiência e as inserções existenciais na forma de ações que tais interpretações sugerem. ${ }^{16}$ Digo mais genericamente interpretações e não apenas, estritamente, conceituações, para abarcar semioticamente signos interpretantes que não se restringem aos de classe lógica, lembrando-nos, por exemplo, de como interpretantes emocionais também fazem incorrer em modos de agir.

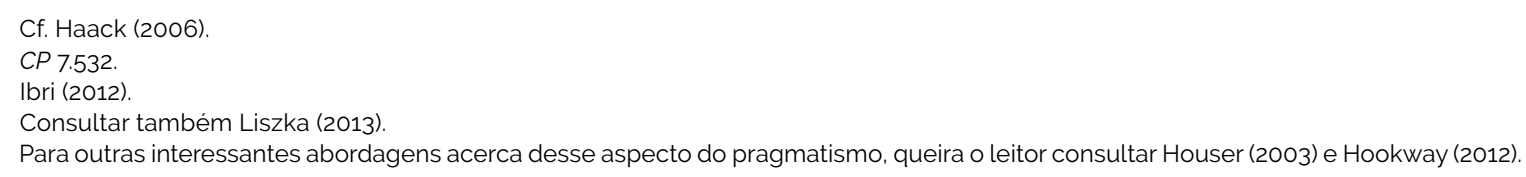


Há já aqui, considero, muita filosofia e ainda falta-nos retomar a mais original categoria peirciana, a primeiridade. Nela está reservada aquela classe de experiência que nos permite sair do jugo do Chronos, cujo fluxo inexorável sabemos independer de nossa vontade. Fenomenologicamente temos consciência, e não é necessário ir além do senso comum para isso, de que o passado não é revogável e que no futuro está a possibilidade de reafirmação de nossos acertos ou correção de nossos erros. Essa quase onipresença do Chronos em nossa experiência de existir, e tomo aqui, uma vez mais, existência em seu sentido de segundidade, se faz simultaneamente com nosso convivio praticamente ubiquo com a terceiridade, seja na forma de hábitos bem sucedidos como guias de ação, seja como investigações cognitivas que buscam representar os estados de coisas reais e prever sua conduta futura.

Contemplarmos simplesmente o mundo, em uma experiência desinteressada porque sem propósito prático, permite desmobilizar as formas conceituais que medeiam nosso agir no mundo. Essa categoria de experiência pode alhear-se do Chronos porque não necessita da continuidade das formas lógicas que representam as formas lógicas da realidade. ${ }^{17}$ Trata-se de uma experiência que pode ser puramente sensivel, em que a consciência é constituída por qualidades de sentimento. Podemos, nessa experiência, vivenciar a ausência de reação do mundo, dele como alteridade, percebendo nele apenas suas formas, cores, odores, sons e, principalmente, sua diversidade e assimetria.

É importante acentuar que se tem afirmado, entre os estudiosos da obra peirciana, a onipresença das categorias, uma forma de considerar que primeiridade, segundidade e terceiridade nunca se apresentam isoladamente, mas sempre como uma tríade. Isso é verdadeiro, penso, enquanto elas são tomadas como estruturantes da realidade, mas não necessariamente enquanto experienciadas fenomenologicamente. Em outras palavras, tal onipresença se dá no objeto dinâmico, mas não necessariamente no plano do objeto imediato. ${ }^{18}$

Peirce é claro ao descrever as experiências de pura primeiridade e, também, de pura segundidade. ${ }^{19}$ Livrar-nos da forma lógica, judicativa, por vezes em nossas vidas, é um privilégio que nos permite experienciar uma consciência de unidade. Essa é, a propósito, a essencial característica da experiência estética em seu estado mais genético. ${ }^{20}$ Apenas sentir tal unidade, típica do que Peirce denomina qualeconsciência, sem experienciar a reação do mundo, é, em verdade, um abdicar, pela sua desnecessidade como mediação, da terceiridade em todas as suas formas, seja como pensamento investigativo, seja como hábitos de conduta - ambos envolvem autocontrole em face da alteridade e, por consequência, uma consciência de fluxo do tempo Chronos.

Muitas filosofias que não distinguem realidade objetiva, duramente outra, independente de nós, de suas representações ou dos modos como sentimos o mundo, dificilmente distinguem a alteridade do Chronos daquilo que a sabedoria grega já denominava Kairós, uma temporalidade subjetiva, que tinha nos Estoicos, por exemplo, relações com a noção de destino e momento de vida. ${ }^{21}$ Em verdade, um simples espelho pode denunciar a ilusão de um tempo que aparentemente não flui, no mais das vezes nutrido pelo tédio de hábitos obnubilantes.

O realismo das formas contínuas na filosofia de Peirce requer o Chronos como parte própria da realidade da terceiridade. Há, nesse realismo, o reconhecimento de um Cosmos dinâmico, uma ordem objetiva em fluxo, que radicalmente independe de nossa subjetividade. ${ }^{22}$

\footnotetext{
17 Essa simetria de vocabulário é facultada pelo realismo da filosofia de Peirce.

18 Em termos semioticamente bastante gerais, o objeto dinâmico caracteriza-se por ser independente de suas representações, enquanto o imediato é aquele contido em tais representações.

19 Verifique-se, por exemplo, CP 1.304-324.

20 Confira-se, por exemplo, Ibri (2009, 2010), Anderson (1987) e Sebeok (1991) para outras abordagens acerca deste tema.

${ }_{21}$ Aproprio-me do termo Kairós, que tem desdobramentos conceituais variados na cultura grega, pelo viés de subjetividade comum a todos eles, e que aqui me interessa na distinção que proponho com respeito ao caráter objetivo do tempo Chronos.

22 Ver também Houser (2014).
} 
A aparente perda poética dessa dessubjetivação do tempo, reclamável, talvez, por filosofias marcadamente antropocêntricas, tem, ao contrário, a meu ver, um ganho de qualidade estética. De um lado, podemos nos recolher na interioridade de um Kairós que remete a um universo contínuo de qualidades, primeiridade pura, constitutiva elementar do conceito de consciência em Peirce, alheando-nos da vontade de um querer que mobiliza a reação do mundo. Trata-se de uma experiência que demanda, para sua consideração objetiva, e não meramente psicológica, uma lógica das possibilidades, que irá incorrer na obra peirciana em uma filosofia genética, aquela que deve reunir suficiente potência teórica que permita formular para si questões de origem, não apenas relacionadas a uma arqueologia do saber, ${ }^{23}$ mas, também, sobre uma ontologia cosmo-originária de todos os fenômenos.

Não são poucas as passagens na obra de Peirce que atribuem a essa experiência o caráter originário de toda heurística. ${ }^{24}$ Nesse sentido, reputo que a desconsideração da Cosmologia de Peirce, ou mesmo sua negação como importante capítulo de sua obra, acaba incorrendo na renúncia em pensar a genética de suas categorias, pagando-se o alto preço de assumi-las dogmaticamente no interior de uma filosofia que poderia receber muitos selos, menos, penso eu, de ser dogmática. A Cosmologia de Peirce requer, para seu estudo, a meu ver, o abandono do seguro conforto da lógica dedutiva, ${ }^{25}$ aceitando-se o desafio de se pensar de modo conjectural uma lógica das possibilidades. ${ }^{26}$ Como recompensa, nela se encontrará a mais radical demonstração do que seja uma filosofia genética, como também queria, a propósito, Schelling, ${ }^{27}$ por quem Peirce alimentou grande admiração. ${ }^{28}$
Permito-me novamente retomar o ganho poético da distinção entre Chronos e Kairós, observando que para a percepção de qualidades dos objetos do mundo, necessitamos abandonar as mediações conceituais que deles selecionam sempre aquilo que recebe nomes, deixando de lado justamente o que não pode ser generalizado porque idiossincrático, singular e, por assim ser, ineptos a integrar classes de predicados que sustentam substantivamente nossa linguagem. Abdicar das mediações de terceiridade é abster-se da percepção do Chronos, facultando perceber as coisas sem nome, ${ }^{29}$ que, em verdade, constituem o objeto mais genuíno da criação artística. Essa percepção do que não interessa ao conceito pode se fazer por uma consciência de presentidade, em que Kairós é uma espécie de fluir vertical pela descontinuidade do presente de um Chronos que, indiferente às representações de suas qualidades, flui horizontal e fatalmente do passado para o futuro. A sensibilidade do poeta deveria agradecer, suponho, a generosidade de um Chronos que, ao dispor em si do hiato do presente para a participação do princípio do Acaso na existência, oferece, também, o espaço objetivo no qual Kairós pode resgatar aquele resíduo de realidade não generalizável que a rede lógica das mediações tem necessariamente de pôr à margem para que sua função de iluminar preditivamente o futuro seja possivel.

Creio que essa representação do tempo subjetivo como vertical à horizontalidade do tempo objetivo, como mostra de modo simples o esquema a seguir (Figura 1), é útil para tornar o conceito de presentidade, sobre o qual Peirce insistiu, conciliável com essa introdução que aqui faço das distinções entre Chronos e Kairós.

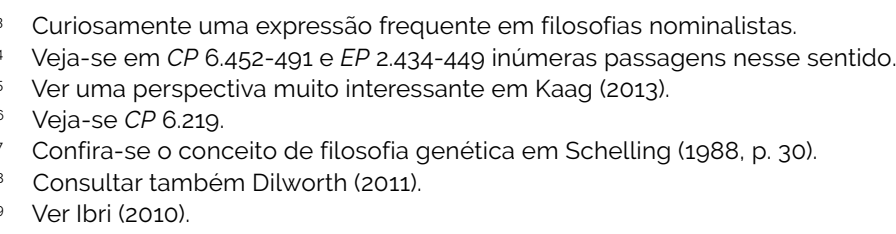


Figura 1 - Representação do tempo subjetivo como vertical à horizontalidade do tempo objetivo

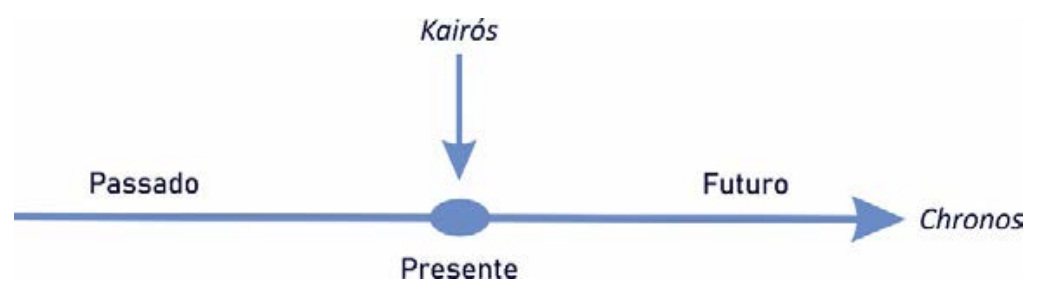

Fonte: Elaborado pelo autor exclusivamente para esse texto.

A título meramente ilustrativo sobre como se daria essa interação de ambos os tempos, objetivo e subjetivo, imaginemos, exemplarmente, dois estados experienciais. Um primeiro em que estivéssemos simplesmente ouvindo uma suave música e deixássemos que ela preenchesse a totalidade de nossa consciência, sem que nela se inserissem quaisquer juizos sobre essa experiência que, a propósito, a tornariam representada, mediata, e não imediata como de fato ela ocorre no simples curso sensivel dos sons audiveis. Parece ser evidente que tal experiência seria marcada pelo contínuo fluir interior dos signos musicais associado a uma temporalidade também apenas interior. Do mesmo modo, se poderia afirmar que o Chronos como tempo objetivo exterior estaria fluindo em seu continuum próprio, sob sua categorial segundidade, independentemente dessa experiência meramente subjetiva. A hipótese dessa dissociação entre essas duas classes de tempo baseia-se na possibilidade fenomenológica de nossa humana consciência se alhear da alteridade dos fenômenos, desmobilizada que estaria de quaisquer atos de natureza volitiva. Uma relação desinteressada com o mundo proporcionaria uma experiência meramente lúdica - dir-se-ia dela, estética. Pode-se reportar, também a título de exemplo, a uma experiência de mera contemplação de um objeto - imagine-se um recorte da Natureza, no qual uma consciência estaria imersa, tomada, apenas, pelas qualidades sensiveis ostensivamente imediatas - consciência, a propósito, nomeada por Peirce de qualeconsciência. Do mesmo modo, ter-se-ia uma distinção entre
Chronos e Kairós, evidentemente não perceptível no momento em que tal experiência ocorresse. mas apenas como representada a posteriori. ${ }^{30}$

Não obstante a filosofia de Peirce não dispor de uma reflexão sobre arte sequer próxima do nivel em que tratou suas demais doutrinas, considero seu sistema teórico extremamente proficuo para esse desenvolvimento temático, mormente no que respeita a uma ontologia da arte, ${ }^{31}$ uma vez que o início dessa reflexão teria por ponto de partida a natureza ontológica das coisas sem nome. ${ }^{32}$

Que papel a Arte desempenha na construção de mediações que não podem ser concebidas dentro de formas lógicas típicas da terceiridade, uma vez se originarem de elementos da experiência que repugnam qualquer generalidade? Essa questão eleva a atividade artística para além da produção de signos conducentes à mera fruição lúdica, a qual seria, como propus em outras ocasiões, uma espécie de repouso do guerreiro, um breaking point em nossa exaustiva missão de problems solvers. ${ }^{33}$ Haveria nela, nessa suposta função mediativa, uma conotação moral e, deste modo, afetante da conduta? Deixarei por ora, todavia, essas considerações, para antes tratar do caráter ético do pragmaticismo de Peirce.

\section{A vela ética do pragmaticismo}

O início da filosofia madura de Peirce por uma Fenomenologia, como afirmei no início desse texto, se inicia por um estar no mundo, comprometendo-a com todo o universo da experiência.

\footnotetext{
30 A propósito, a respeito da descrição de experiência desinteressada e do tempo na experiência estética convoque-se Schopenhauer (1969), sobre quem comento na conclusão desse ensaio.

31 Para outras perspectivas, consultar, por exemplo, Parret (1994) e Dilworth (2010)

32 Desenvolvi um esboço nessa direção em Ibri (2010)

33 Ver também Mayorga (2013) e Maddalena (2010).
} 
Tal genética não implica em qualquer concessão a um empirismo tal qual formulado no século dezoito e propriamente criticado por Kant. Toda interpretação, para Peirce, convém assinalar, já envolve formas fenomênicas de experiência. ${ }^{34}$

Distante, assim, de qualquer escola sensacionalista e de uma interpretação empirista de sua fenomenologia, o caráter originário do pensamento peirciano, na medida em que envolve experiência interpretada que se torna o próprio curso da vida, já nasce como uma filosofia da conduta, ou seja, já se torna geneticamente pragmática. É natural que tal comprometimento com o curso da vida devesse, como de fato o faz, recusar toda forma de ceticismo que deixasse à margem o modo como se desenham as ações humanas. Agir, aqui, se faz à luz de interpretantes reflexionados, a saber, que retornam ao lado potencialmente público, observável por qualquer mente envolvida nesse universo experiencial. A ação, assim concebida, torna-se o lado externo que determina existencialmente o interpretante a ela associado. Conduta, na forma em que ela é possivel de ser generalizada propiciando sua interpretação cognitiva, consuma a noção de significado implicada na máxima do pragmaticismo. ${ }^{35}$ Por conseguinte, o significado dos conceitos, ou utilizando o vocabulário da Semiótica, dos interpretantes lógicos, condicionam a ação. Esse compromisso semântico entre o lado interno do conceito, sua terceiridade, e seu aparecer exterior, determinadamente público como segundidade, perfazendo o que recomenda a máxima do pragmatismo, tem em seu fundo um caráter ético, ${ }^{36}$ por vincular linguagem, cognição, teoria positiva com pretensões fáticas, com seu aparecimento exterior como conduta. Há, aqui, uma regra de harmonia necessária entre linguagem intencionada e ação dela decorrente, que o mais simples senso comum reconhece e requer nas relações humanas.

É também interessante destacar que a máxima do pragmatismo sugere um vínculo entre cognoscibilidade e eticidade. ${ }^{37} \mathrm{O}$ lado interno deve aparecer como externo e, ao fazê-lo, perde sua generalidade indeterminada para ser determinação dentro de um teatro de reações. Essa condição é axial para se constituir uma metafísica sã na qual a terceiridade real possa ser e ser representada. Ora, essa condição de cognoscibilidade torna-se condição de eticidade, uma vez que a conduta - na medida em que se dá na esfera potencialmente acessivel a qualquer mente cognoscente - deve apontar para a verdadeira forma que promove a ação. Falsas teorias, sobre qualquer recorte da realidade, e discursos que dissimulam fins intencionalmente velados têm em comum a quebra da regra semântica de harmonia entre segundidade e terceiridade requerida pelo pragmatismo, na medida em que suas consequências adentrem o universo aberto a toda possivel experiência e interpretação. ${ }^{38}$

Vale dizer, a bem da ontologia realista de Peirce, que esse quesito de harmonia extrapola o que comumente se costuma denominar verificacionismo das teorias. No mais das vezes, tal expressão é vazia de qualquer ontologia e exime os que a empregam de justificar por que se deva dar a última palavra aos fatos. Esse, na verdade, é um dos dilemas lógicos cruciais, a meu ver, das epistemologias nominalistas. $\bigcirc$ pragmaticismo, de sua vez, compreendido à luz das categorias e tendo sua validade lógica estendida a uma ontologia legitimada pela simetria das categorias, pode afirmar essa relação necessária entre esferas interior e exterior dos fenômenos e comprovar tal relação nas predições de conduta futura dos objetos. As formas lógicas, tomadas na sua simetria realista e, portanto, válidas tanto para os signos quanto para seus objetos, devem ter permanência futura, aparecendo determinadamente como história fática acessivel a toda mente experienciadora.

Esse compromisso pragmático entre ser e aparecer, lado interno constituido pelas continuidades

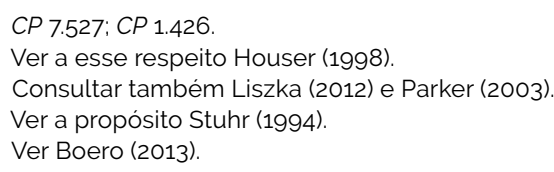


e lado externo formando elementos discretos por elas produzidos, cumprem, como afirmei anteriormente, um quesito necessário de eticidade, a par de sua condição epistemológica. Porém, o caráter ético de uma conduta deve estar associado à sua finalidade, para a qual tal conduta se tensiona. Assim, parece legitimo dizer que a condição de harmonia pragmática satisfaz uma condição necessária, mas não suficiente, a saber, a questão tão conhecida dos estudiosos de Ética e em particular das ciências normativas de Peirce: ${ }^{39}$ qual o valor moral do fim a que se destina a conduta?

Antes de tentarmos responder a essa pergunta à luz da filosofia de Peirce, cabem, ainda, mais algumas considerações sobre as relações entre cognoscibilidade e eticidade. É sabido que o quesito consequências práticas, presente na máxima do pragmatismo, significa influência na conduta, e estamos considerando conduta como um conjunto de ações intencionadas para algum fim. Sob esse ponto de vista, pode-se entender a máxima de um modo bastante amplo, pois satisfaz não apenas o aparecer do que está sob as formas lógicas da terceiridade, como sob os contínuos de possibilidade que constituem a primeiridade. Das primeiras, surge uma faticidade que deve denotar algum hábito no objeto e facultar a constituição de hábitos na mente cognoscente. Dos contínuos de primeiridade, resulta faticidade aleatória, que revela a realidade de um princípio de liberdade, que Peirce denominou Tiquismo (Tychism), atuante nos objetos.

Essa condição de significação, simultânea à de cognoscibilidade, como passagem necessária do lado interno para o externo, pode ser entendida, no plano da eticidade, utilizando-se um termo heideggeriano, como a passagem do oculto que se desvela, dando-se ao conhecimento de outras mentes. Esse é o sentido que tenho empregado com respeito à expressão potencialmente público.

Seré ser cognoscive ${ }^{40}$ é uma equação peirciana que cabe ser explorada no plano ético. A eticidade da máxima está nessa necessidade de revelação do lado interior - a forma oculta não participa do diálogo reflexivo com a alteridade do real.

Desvelar-se, no sentido em que se está tratando o termo, não seria uma generosa concessão para a alteridade, mas uma necessidade de ser em sentido pragmático, a saber, de adentrar um teatro de reações no qual o conceito de ser se defina pragmaticamente por participar da dialógica reflexividade semiótica entre mundos interno e externo.

Physis kriptestai philei - A Natureza ama se esconder - é uma famosa máxima de Heráclito. ${ }^{41}$ Seu sentido fica confinado a uma era pré-científica, pois parece ser injusto nos queixarmos da ocultação dos objetos naturais, face ao sucesso crescente do esforço humano em conhecê-los. Transportada essa máxima para a conduta humana, como alguns pensadores o fizeram, ela se referiria ao plano da Ética - formas ocultas, não obstante, moldam condutas, como mostra The Fixation of Belief de Peirce. Retomemos esse ensaio, brevemente, para tentar exibir sua face de eticidade.

\section{Eticidade pragmática nas formas de crenças}

The Fixation of Belief, ${ }^{42}$ texto de juventude de Peirce, quando analisado à luz de seu sistema maduro de doutrinas, pode-se dele ter uma visão mais ampla e, penso eu, mais profunda de seu significado. Esse fato parece confirmar a expectativa de que o estudo de textos específicos do autor, tendo-se, antes, passado pelo entrelaçamento lógico de suas principais doutrinas, enriquece a leitura de seus escritos mais precoces. Uma razão possivel para isso é a aquisição de um vocabulário mais rico e de uma consciência mais aguda que reputo muito importante do realismo de Peirce.

Tendo-se em mente os quatro tipos de fixação de crenças - lembremos: tenacidade, autoridade,

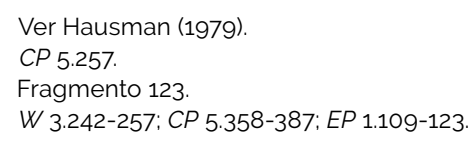


a priori e científica - creio ser possivel classificar os três primeiros como dogmáticos ${ }^{43} \mathrm{e}$ o último como semioticamente dialogante. Utilizo aqui o predicado dogmático para caracterizar deles uma terceiridade que não dialoga com a experiência, como os casos da tenacidade e a priori, ou o faz privadamente, como o método da autoridade. O método da tenacidade constitui uma crença que se cristaliza por ignorar ou se afastar de toda experiência capaz de contrariá-la. As crenças a priori, de sua vez, não podem exibir as formas nas quais creem, porque elas estão além de toda experiência possivel. Em ambos esses tipos de crenças há o truncamento do diálogo semiótico com uma realidade que implementaria a vivacidade e a atualização da forma lógica da crença. Ambas não modificam conduta porque nada podem aprender, tomando-se aqui o conceito de aprendizagem sob a ótica do pragmaticismo. Evidentemente, crenças a priori podem criar discursos cuja pretensão de veracidade alimenta-se da ilusão expressa pela metáfora da pomba de Kant ${ }^{44}$-seus objetos inacessiveis não podem reagir ao que deles se afirma.

Interessante é perceber que, malgrado sejam crenças que não se credenciam pelo diálogo semiótico potencialmente renovador de suas formas, elas permanecem moldando a conduta, em um aparente preenchimento da condição de sentido pragmático. Contudo, a crença tenaz será vítima de seu isolamento experiencial, sendo quase impossivel ser partilhada para além de um pequeno e fechado grupo. As crenças a priori, que sustentam, por exemplo, discursos teológicos, criam dentro de seu âmbito, no mais das vezes, uma moralidade baseada em recompensas transcendentes - há uma faticidade histórica abundante de exercício de poder e crueldade nelas baseada. A crítica de Kant à metafísica não científica não era tão somente epistemológica, mas, pode-se supor, trazia em seu bojo, também, - alerta iluminista contra o possivel terror da autoridade que se autocredenciava por formas ocultas.

Muito mais se poderia dizer sobre essas duas formas de crença, mas, para os fins deste ensaio, basta-nos pensar como elas não dialogam com a experiência, e consequências práticas implicam em sua renovação reflexionada por um diálogo semiótico dinâmico e constante entre mundos interno e externo. Estacionar em qualquer um desses mundos é truncar o curso de aprendizagem constante requerido pelo pragmaticismo. ${ }^{45}$

O método da autoridade, quando não decorre das crenças a priori que com ele têm estreita proximidade, privatiza seu diálogo com a experiência e não partilha os interpretantes que dele decorrem. Ele pode ser eficiente, como o próprio Peirce reconhece, ${ }^{46}$ mas a comunidade que é submetida aos ditames da autoridade fica marginalizada daquele diálogo. Fins gerais ${ }^{47}$ requeridos por uma eticidade pragmática não soem ser atingidos por esse método.

Por fim, as crenças científicas se credenciam pelo seu caráter público, seja no que respeita às formas que estruturam suas teorias, quanto aos objetos a que se referem, abertos à visitação comum. Sua genética das mediações, dos interpretantes, é partilhada de modo que as crenças se justifiquem pelo seu incessante diálogo com a experiência. Nelas não cabe o oculto, o privativo, tampouco qualquer modo de autoridade, e não por outra razão a atividade científica constitui comunidade genuina, que Peirce poderia legitimamente denominar comunidade de investigação. ${ }^{48}$

Essa constituição de comunidade cujo fim é a busca incessante de representações verdadeiras da realidade, é um dos eixos da inspiração peirciana para lastrear sua ideia de eticidade. A verdade, como um fim, já institui uma conduta com ele comprometida ${ }^{49}$ e, no plano da comu-

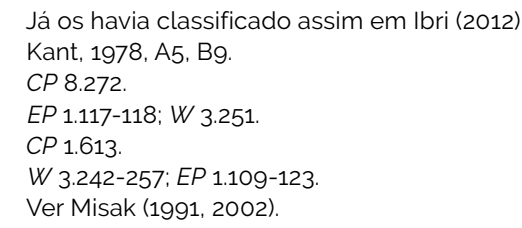


nidade científica, o processo semiótico-dialógico é o meio pelo qual esse fim pode ser colimado ${ }^{50}$.

\section{A incessante busca da forma}

Uma filosofia genética não pode admitir uma forma como origem, sob pena de adotar um início dogmático. Pode-se conceituar ontologicamente genética toda filosofia que permite pensar o estado zero, de absoluto Nada, como afirma Peirce em sua Cosmogênese. Nesse contexto, é historicamente interessante resgatar a critica de Hegel ${ }^{51}$ a Schelling em sua Fenomenologia do Espírito, na qual a famosa passagem De noite todos os gatos são pardos, recusa a amorfa natureza do Absoluto, presente na Filosofia da Identidade ${ }^{2}$ schellinguiana. Hegel, de sua vez, parte da realidade da Razão divina, que sugere pensar um possivel retorno ao dogmatismo metafisico criticado por Kant.

Peirce é, nesse aspecto, totalmente adepto de Schelling, conforme mostra sua Cosmogênese. As categorias surgem evolucionariamente na direção da Forma da Terceiridade, e aqui cabe, à luz desse conceito de forma, admitir que tanto a primeiridade quanto a segundidade não têm forma, mas são apenas modos de ser do que cosmicamente é liberdade e existência. Todo o curso da evolução se dá na direção da constituição da Terceiridade, a saber, de leis e hábitos que atuam como mediações que garantem a continuidade da forma como realidade e, deste modo, a inteligibilidade do universo.

Talvez possa parecer estranha a afirmação de que a primeiridade seja destituída de forma, mas, tomado o conceito de forma como uma rede de relações lógicas tal como estruturam hábitos e leis, o caráter lógico da primeira categoria está associado apenas à possibilidade:

Primeiridade é o modo de ser que consiste em seu objeto ser positivamente tal qual é sem consideração a nada mais. Isso somente pode ser uma possibilidade. Pois, enquanto as coisas não agem umas sobre as outras, não há sentido ou significado em dizer que elas possuem qualquer existência, a menos que isso signifique que elas são de tal modo em si mesmas que possam, talvez, vir a se relacionarem com outras coisas. ${ }^{53}$

Contudo, possibilidades, em seu caráter geral, constituem continuidades ${ }^{54}$ sem forma em face da ausência de regras que pudessem condicionar suas réplicas como segundidade: Acaso puro produz apenas eventos independentes.

Fenomenologicamente, conforme dito anteriormente, qualeconsciência, na qual a primeiridade é manifesta, é uma experiência cujo predicado lógico é sua unidade como contínuo de possibilidades. Qualidades de sentimento, enquanto pura experiência de primeiridade, têm a unidade de uma continuidade sem formas. Compare-se, de modo exemplarmente simples, o contínuo de um plano e o contínuo de todos os triângulos possiveis de serem construídos sobre ele. No primeiro caso, a continuidade não tem forma; no segundo, há, ao menos, uma regra geral que impõe a condição de possibilidade de uma figura geométrica ser triangular. ${ }^{55}$

Interessante é percorrer a filosofia de Peirce e notar nela, pelo seu caráter genético, uma onipresença do vetor da não forma para a forma. Ontologicamente, não é outro o direcionamento da cosmogênese. Do mesmo modo, nesse sentido, identificam-se os processos de semiose, abdutivos, de constituição do universo simbólico, seja humano, seja natural, pelas generalizações advindas de um diálogo com a alteridade na construção de mediações. Há em comum entre eles a passagem da generalidade do sentimento para generalidade da inteligência que o incorpora, como de fato faz o caráter triádico da terceiridade.

Vejo importante, também, associar, de gênese, as duas faces da primeiridade, a saber, o seu modo de ser interior, como unidade das qualidades de sentimento, e seu aparecer exterior como

\footnotetext{
50 Esse entendimento ético da cientificidade não parece ter sido apreendido por Apel (1981), que acusa Peirce de praticar uma filosofia cientificista.

51 Hegel, 1977, § 16 .

52 Schelling (1988)

$53 \mathrm{CP} 1.25$.

54 CP 4.172, grifos meus. Examinar também CP 5.526-532 e 7.209.

55 Acerca do conceito de continuidade em Peirce, consultar, por exemplo, Moore (2003) e em outra perspectiva, Lane (2011).
} 
diversidade, tal qual, a propósito deveria ser, uma vez que a essa categoria se aplicaria apenas o que Peirce denomina lógica da liberdade ${ }^{56}$ ou das possibilidades: "Onde quer que a espontaneidade do acaso seja encontrada, lá existe sentimento na mesma proporção. De fato, acaso nada é senão o aspecto externo daquilo que internamente em si mesmo é sentimento".57 Aqui nos lembramos de como as coisas sem nome, o irregular que repudia o conceito, inspiram justamente os artistas, os que sabem se entregar ao Kairós porque ele generosamente oferece a unidade no que aparece como fragmento. Não apenas eles, artistas, mas todos os que vivenciam, na experiência estética, o resgate de uma unidade de natureza interior, na qual a comoção trazida, exemplarmente, pela Ária na corda sol de Bach, sugere uma nostalgia de origem, ${ }^{58}$ utilizando-se uma expressão de Schelling. $O$ entendimento mais profundo desse resgate é proporcionado por se ter tomado com boa vontade crítica o estudo da Cosmologia de Peirce.

A reflexão sobre o vetor que nasce da origem da espontaneidade sem forma para a forma da terceiridade, passando pelo teatro da existência dado pela categoria da segundidade, conduz a um princípio heurístico cuja abordagem torna-se proibitiva em face do espaço reservado ao presente ensaio. Mencioná-lo, contudo, permite lembrar, a meu ver, que a filosofia peirciana pode ubiquamente ser predicada de heurística e os modos de passagem dos contínuos de possibilidade para os de quase necessidade ${ }^{59}$ sugerem uma reflexão sobre as distintas, não obstante correlatas, semioses promovida pela arte e pela ciência, vistas com foco em uma ontologia de seus objetos.

\section{A Forma Viva do Admirável}

Considere-se, como se sabe, que de acordo com Peirce a "Estética é a ciência dos ideais, ou daquilo que é objetivamente admirável sem qualquer razão ulterior". 60 Observemos as seguintes passagens de sua obra:

O objeto admirável, que é admirável per se deve, sem dúvida, ser geral. Todo ideal é mais ou menos geral. Pode ser um estado complicado de coisas. Mas deve ser um ideal único: deve possuir unidade, porque é uma ideia, $e$ a unidade é essencial em toda ideia e todo ideal (grifo nosso). ${ }^{61}$

Por consequência, o pragmaticista não faz com que o summum bonum consista em ação, mas o faz consistir no processo evolucionário pelo qual o existente encarna mais e mais aqueles gerais aos quais, acabamos de dizer, estão destinados, que é o que nos esforçamos por expressar ao chamá-los de razoáveis. ${ }^{62}$

À luz dessas passagens, parece-me legitimo dizer que razoabilidade, como fim geral último da Ética e como summum bonum, poderia ser representada por um diagrama pragmático, a saber, uma forma semiótica dinâmica, tensionada para sua exterioridade, como devem ser as formas que não se ocultam, mas que realizam sua potencialidade na direção de um crescimento contínuo. Penso que a admirabilidade que Peirce lhe atribui está no caráter de sua forma que proporciona não somente a unidade interior de uma experiência estética quando se a contempla, mas também na sua efetividade como prática de vida, portanto, em seu caráter pragmático em que os seres que a têm como fim contribuem comunitariamente para seu crescimento. Comunitariamente, porque essa é, ao fim e ao cabo, a natureza social do vetor de busca de formas mediadoras. Crescimento, por efeito de exercicio de liberdade criadora - o efetivo exercício das três categorias, no qual a primeiridade tem papel genético, sem o que, aludindo ao esquema de A Fixação da Crença de Peirce, as formas tendem a ser tenazes, autoritárias ou transcendentes, ocultas em seu dogmatismo e

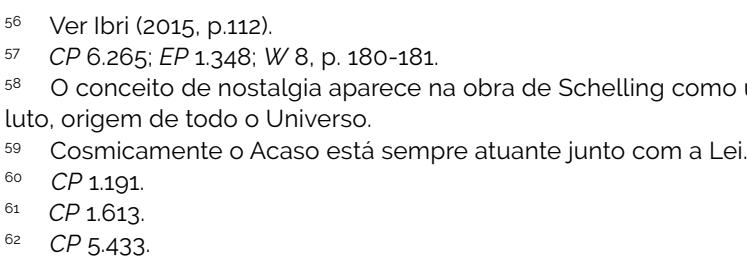


fontes de todo possivel mero exercício de poder que está potencialmente implicado na natureza de fins sempre privativos, mesmo aqueles encobertos por vestimentas sociais. Valho-me do substantivo poder para, de um lado, designar toda ação cujo fim último estaria exclusivamente sob a segundidade: nele está a conduta submetida a todos os modos de força bruta. De outro lado, o termo designaria a decorrente solidão final dos dogmáticos, colhida da inversão do vetor conducente ao amplo diálogo semiótico que incorpora a alteridade no crescimento das formas partilháveis comunitariamente.

\section{Considerações finais: àqueles que não ainda experimentaram a unidade genética do belo}

Há um sentido geral nas Cartas de Schiller, ${ }^{63}$ tomado em seu espírito mais que na letra, que propõe o adestramento dos jovens na beleza, na experiência estética que confere unidade e com ela a liberdade lúdica do spieltrieb. A par de associar intimamente criatividade e liberdade, um importante aspecto dessa obra é de caráter ético: o homem educado a amar a beleza tende a adotar condutas que tenham esse predicado. $O$ amor pela beleza talvez se alimente do privilégio que por vezes temos de abandonar o Chronos. Ao fazê-lo, afastamo-nos do cotidiano contato fragmentário com a alteridade e podemos viver a unidade interior do Kairós, o tempo subjetivo que apenas flui verticalmente pelo hiato presente do tempo real. Quando Schopenhauer ${ }^{64}$ afirmou que a música era a arte exclusivamente experienciada no tempo, esqueceu-se, a meu ver, de dizer a que tempo se referia. A bem dessa distinção, suponho ser a música a arte mais apta a proporcionar a uma fenomenológica ruptura de nossa consciência com o Chronos, mergulhando-a como qualeconsciência em um Kairós, cuja natureza interior se alheia de toda objetidade. ${ }^{65}$ Sob essas considerações, parece tornar-se essencial a distinção entre as duas formas de tempo tal como aqui propostas.
Toda unidade vem dessa interioridade sem forma do mero qualissigno, manifestando sua dimensão originária de primeiridade. Ela é heurística, geradora de criações e descobertas; e vale lembrar que, na filosofia peirciana, ela substitui a unidade sintética do eu penso kantiano pela qualeconsciência que dá unidade aos juizos perceptivos. Buscá-la na existência submetida ao Chronos é concebê-la necessariamente em uma Forma, porque estaremos sendo convocados a quebrar a força bruta da segundidade, tornando-a mais razoável. A Forma que pragmaticamente o fizer de modo eficientemente geral integrando todos os seres que ela medeia, terá o predicado da beleza e será legitimada como admirável.

Talvez estejamos, como comunidade, ainda muito distantes desse ideal de conduta apregoado por Peirce. Enquanto tal ideal não se consuma existencialmente por muitas circunstâncias, não obstante uma vez crendo nele, busquemos agir em sua direção, podemos vivenciá-lo em sua expressão interior na unidade da experiência estética. Bach, Mozart, Brahms e Mahler generosamente sempre se prontificarão a mostrá-lo.

\section{Referências}

\section{Obras de Charles Sanders Peirce}

PEIRCE, Charles Sanders Peirce. Collected Papers of Charles Sanders Peirce. Edited by Charles Hartshorne, Paul Weiss, and Arthur W. Burks. Cambridge: Massachusetts: Harvard University Press, 1931-35 e 1958, 8 $v$. (Fazemos referência a esta obra na forma usual: $C P$ indica Collected Papers; o primeiro número designa o volume e o segundo o parágrafo).

PEIRCE, Charles Sanders Peirce. Writings of Charles Sanders Peirce: A Chronological Edition. Edited by Max Fisch, Edward C. Moore, Christian Kloesel, Nathan Houser, André De Tienne, et al. 8 vols. Bloomington: Indiana University Press, 1982-2010.

PEIRCE, Charles Sanders Peirce. The New Elements of Mathematics by Charles S. Peirce. Edited by Carolyn Eisele. The Hague, Mouton Publishers, 1976. v. 4. (A menção a esta obra, ao longo do trabalho, é efetuada na forma abreviada NEM, associada à página correspondente do quarto volume da edição utilizada). 
PEIRCE, Charles Sanders Peirce. The essential Peirce: Selected Philosophical Writings. V. 1. Edited by Nathan Houser and Christian Kloesel. Bloomington: Indiana University Press, 1992. (Citado EP, seguido do número correspondente ao volume e do número da página).

PEIRCE, Charles Sanders Peirce. The essential Peirce: Selected Philosophical Writings. v. 2. Edited by the Peirce Edition Project. Bloomington: Indiana University Press, 1998. (Citado EP seguido do número correspondente ao volume e do número da página).

PEIRCE, Charles Sanders Peirce. Historical Perspectives on Peirce's Logic of Science. Edited by Carolyn Eisele. Berlin: New York, Amsterdam, Mouton, 1985. 2 V.

PEIRCE, Charles Sanders Peirce. Semiotic and Significs: The Correspondence between Charles S. Peirce and Victoria Lady Welby. Edited by Charles Hardwick. Bloomington: Indiana University Press, 1977.

PEIRCE, Charles Sanders Peirce. Charles Sanders Peirce: Contributions to the Nation. Edited by Kenneth Ketner and James Edward Cook. Lubbock: Texas Tech Press, 1975-1987. $4 \mathrm{~V}$.

PEIRCE, Charles Sanders Peirce. Reasoning and the Logic of Things: The Cambridge Conferences / Lectures of 1898. Edited by Kenneth Ketner. Cambridge: Massachusetts, Harvard University Press, 1992.

PEIRCE, Charles Sanders Peirce. Studies in Logic by Members of Johns Hopkins University (1883). Edited by Charles Sanders Peirce. Amsterdam: Philadelphia, John Benjamins Publishing, 1983. https://doi.org/10.1075/fos.1.

PEIRCE, Charles Sanders Peirce. Annotated Catalogue of the Papers of Charles S. Peirce. Richard Robin (org.). The University of Massachusetts Press, 1967.

\section{Outras obras}

ANDERSON, Douglas R. Creativity and the Philosophy of C. S. Peirce. Dordrecht, Netherlands: Martinus Nijhoff Publishers, 1987. https://doi.org/10.1007/978-94-015-7760-1.

APEL, Karl-Otto. From Pragmatism to Pragmaticism. Amherst: University of Massachusetts Press, 1981.

BOERO, Hedy. Peirce's View of the Role of Ethics in Scientific Inquiry. Cognitio, São Paulo, v. 14, n. 1, p. 2333. jan./jun. 2013.

COLAPIETRO, Vincent M. Peirce's Approach to the Self: A Semiotic Perspective on Human Subjectivity. New York: State University of New York Press, 1989

COLAPIETRO, Vincent M. Pragmatism and Psychoanalysis - C. S. Peirce as a Mediating Figure. Cognitio, São Paulo, v. 7 n. 2. p. 189-206. jul./dez. 2006.

DILWORTH, David. Peirce's Objective Idealism: A Reply to T. L. Short 'What was Peirce's Objective Idealism. Cognitio, São Paulo, v 12, n. 1. p. 53-74. jan./jun. 2011.

DILWORTH, David. Elective Metaphysical Affinities: Emerson's "Natural History of Intellect" and Peirce's Synechism. Cognitio, São Paulo, v. 11, n. 1. p. 22-47. jan./jun. 2010.
HAACK, Susan. The Legitimacy of Metaphysics: Kant's Legacy to Peirce, and Peirce's to Philosophy Today (Jul. 20, 2011). Polish Journal of Philosophy, v. 1, p. 29-43, 2007. Available at SSRN: https://ssrn.com/abstract=1890791. https://doi.org/10.5840/pjphil20071119.

HAACK, Susan. The Fragmentation of Philosophy: The Road to Reintegration. In: GÖHNER, J.; JUNG, E. M. (ed.). Susan Haack: Reintegrating Philosophy. Cham: Springer, 2006. (Münster Lectures in Philosophy, v 2).

HAUSMAN, Carl R. Value and Peircean Categories. Transactions of the Charles Sanders Peirce Society, Is. l.], v. 15, n.3, p. 203-224. 1979

HEGEL, G. W. F. Phenomenology of Spirit. Translated by A. V. Miller. New York: Oxford University Press, 1976.

HOOKWAY, Christopher. The Pragmatic Maxim: Essays on Peirce and Pragmatism. Oxford, UK: Oxford University Press, 2012. https://doi.org/10.1093/acprof:0so/9780199588381.001.0001.

HOUSER, Nathan. The Intelligible Universe. In: FERNÁNDEZ, Romanini, E. (ed.). Peirce and Biosemiotics: A Guess at the Riddle of Life. Dordrecht: Springer Science Business media 2014. p. 9-32. (Biosemiotics 11). https:// doi.org/10.1007/978-94-007-7732-3_2.

HOUSER, Nathan. Reconsidering Peirce's Relevance. In: BERGMAN, M.; PAAVOLA, S.; PIETARINEN, A.V.; RYDENFELT, H. (ed.). Ideas in Action: Proceedings of the Applying Peirce Conference.. Helsinki: Nordic Pragmatism Network, 2010. p. 1-15. (Nordic Studies in Pragmatism 1).

HOUSER, Nathan. Introduction. In: PEIRCE EDITION PROJECT (ed.). The Essential Peirce Selected Philosophical Writings.. Bloomington: Indiana University Press, 1998. v. 2.

HOUSER, Nathan. Introduction. In: Writings of Charles Sanders Peirce: A Chronological Edition. Indianapolis: Indiana University Press, 2010a. v. 8.

HOUSER, Nathan. Pragmatism and the Loss of Innocence. Cognitio, São Paulo, v. 4. n. 2. p. 197-210. jul./ dez. 2003.

INNIS, Robert. Peirce's Categories and Langer's Aesthetics: on dividing the Semiotic Continuum. Cognitio, São Paulo, v. 14, n. 1, p. 35-50. jan./jun. 2013.

IBRI, Ivo Assad. Kósmos Noétos: A Arquitetura Metafísica de Charles S. Peirce. São Paulo: Paulus, 2015 - obra também disponivel em versão para o inglês Kósmos Noetós: the metaphysical architecture of Charles S. Peirce. [Amsterdam:]: Springer, 2017. (Philosophical Studies Series, v. 131). https://doi.org/10.1007/978-3319-66314-2.

IBRI, Ivo Assad. Peircean Seeds for a Philosophy of Art. In: HAWORTH, K.; HOGUE J.; SBROCCHI, L. G. (ed.) Semiotics: "The Semiotics of Space. New York: Legas Publishers 2010. p. 1-16. https://doi.org/10.5840/ cpsem201015.

IBRI, Ivo Assad. Choices, Dogmatisms and Bets: Justifying Peirce's Realism. Veritas, PUCRS, Porto Alegre, v. 57, n. 2: 51-61, 2012. https://doi.org/10.15448/19846746.2012.2.13310. 
IBRI, Ivo Assad. Reflections on a Poetic Ground in Peirce's Philosophy. Transactions of the Charles S. Peirce Society, [s. l.], v. 45, n.3, p. 273-307. 2009. https://doi. org/10.2979/tra.2009.45.3.273.

IBRI, Ivo Assad. The Heuristic Exclusivity of Abduction in Peirce's Philosophy. In: FABBRICHESI LEO, Rossella; MARIETTI, Susana (ed.). Semiotics and Philosophy in C. S. Peirce. Cambridge: Cambridge Scholars Press, 2006.

KAAG, John. Returning to the Unformed: Emerson and Peirce on "The Law of Mind". Cognitio, São Paulo, v. 14 . n. 2, p. 189-201, jul./dez. 2013

KANT, Immanuel. Critique of Pure Reason. translation by Norman Kemp Smith. New York: Macmillan Press, 1978.

LANE, Robert. On Peirce's Early Realism. Transactions of the Charles Sanders Peirce Society, [s. l.], v. 40, n. 4. p. 575-605. 2004.

LANE, Robert. The Final Incapacity: Peirce on Intuition and the Continuity of Mind and Matter. (Part 1). Cognitio, São Paulo, v 12, n. 1. p. 105-119. jan./jun. 2011.

LISZKA, James J. Re-Thinking the Pragmatic Theory of Meaning. Cognitio, São Paulo, v. 10, n. 1, p. 61-79. jan./jun. 2009.

LISZKA, James J. New Directions in Pragmatic Ethics. Cognitio, São Paulo, v. 14, n. 1, p. 51-61. jan./jun. 2013.

LISZKA, James J. Charles Peirce on Ethics. In: WAAL, Cornelis de: SKOWROŃSKI, Krzysztof Piotr (ed.). The Normative Thought of Charles S. Peirce. Fordham University Press, New York, 2012. https://doi.org/10.5422/ fordham/9780823242443.003.0003.

MADDALENA, Giovanni. Peirce and Vailati on Semiotics and Freedom. Cognitio, São Paulo, v. 11, n. 1, p. 58-68. jan./jun. 2010.

MAYORGA, Rosa. From Realism to "Realicism": The Metaphysics of Charles Sanders Peirce. Lanham: Lexington Books, 2007.

MAYORGA, Rosa. On the "Beauty of the Unbeautiful" in Peirce's Esthetics. Cognitio, São Paulo, v. 14, n. 1, p. 85-100. jan./jun. 2013.

MAYORGA, Rosa. Peirce's Moral "Realicism". In: WAAL, Cornelis de; SKOWROŃSKI, Krzysztof Piotr (ed.). The Normative Thought of Charles S. Peirce. New York: Fordham University Press, 2012. https://doi.org/10.5422/ fordham/9780823242443.003.0005.

MISAK, Cheryl. C. S. Peirce on Vital Matters. Cognitio, São Paulo, n. 3. p. 64-82. jan./jun. 2002.

MISAK, Cheryl. Truth and the End of Inquiry: A Peircean Account of Truth. Oxford: Clarendon Press, 1991.

MOORE, Matthew. Scotistic Structures. Cognitio, São Paulo, v. 11, n. 1, p. 79-100. jan./jun. 2010.

MOORE, Matthew. The Genesis of the Peircean Continuum. Transactions of the Charles Sanders Peirce Society, [s. l.], v. 43, n.3, p. 425-469. 2007.

PARKER, Kelly. Reconstructing the Normative Sciences. Cognitio, São Paulo, v. 4, n. 1. p. 27-45. jan./jun. 2003.
PARRET, Herman. Peircean Fragments on the Aesthetic Experience. In: PARRET, Herman (ed.). Peirce and Value Theory: On Peircean Ethics and Aesthetics. Amsterdam/ Philadelphia: John Benjamin Publishing Company, 1994. https://doi.org/10.1075/sc.6.

SANTAELLA, Lúcia. Os conceitos anticartesianos do self em Peirce e Bakhtin. Cognitio, São Paulo, v. 7. n. 1, p. 121-132. jan./jun. 2006.

SCHELLING, Friedrich W.J. Ideas for a Philosophy of Nature. Translation by Errol E. Harris and P. Heath. Cambridge: Cambridge at UP; 1988.

SCHILLER, J. C. F. von. On the Aesthetic Education of Man in a Series of Letters. Translated by E. M. Wilkinson and L. A. Willoughby. New York, Oxford University Press, 1982.

SCHOPENHAUER, Arthur. The World as Will and Representation. Translated by E. F. J. Payne. New York, Dover, 1969.

SEBEOK, Thomas A. The Play of Musement. Bloomington Indiana University Press, 1991.

STUHR, John J. Rendering the World more Reasonable: The Practical Significance of Peirce's Normative Science. In: PARRET, Herman (ed.). Peirce and Value Theory: On Peircean Ethics and Aesthetics. Amsterdam/ Philadelphia: John Benjamin Publishing Company, 1994. https://doi.org/10.1075/sc.6.04stu.

\section{Ivo A. Ibri}

Ivo A. Ibri é mestre em filosofia pela PUC/SP, doutor em filosofia pela USP com pós-doutorado pelo Institute for Advanced Study of Indiana University, EUA. É professor titular da Pontifícia Universidade Católica de São Paulo, e doutor da Faculdade de São Bento. Seu trabalho de pesquisa situa-se nas áreas de Filosofia Moderna e Contemporânea, com ênfase em epistemologia, pragmatismo, semiótica, estética e metafísica. É fundador do Centro de Estudos do Pragmatismo do Programa de Estudos Pós-graduados em Filosofia da PUC-SP. É membro do corpo de consultores do Peirce Edition Project at Indiana University, EUA, que edita a obra cronológica de Charles S. Peirce. De 2014 a 2016 exerceu a presidência da Charles S. Peirce Society (EUA). Foi eleito em 2020 presidente honorário da Sociedad Peirce em Latina America, fundada no México em 2019.

\section{Endereço para correspondência}

Ivo A. Ibri

Rua Ministro de Godoi, 969, sala 4E16

05015-901

São Paulo, SP, Brasil 